\title{
VISÕES DE CIÊNCIA EM DESENHOS ANIMADOS: UMA ALTERNATIVA PARA O DEBATE SOBRE A CONSTRUÇÃO DO CONHECIMENTO CIENTÍFICO EM SALA DE AULA
}

\section{Scientific views in cartoons: an alternative for debating about the construction of scientific knowledge in the classroom}

\author{
Nyuara Araújo da Silva Mesquita ${ }^{1}$ \\ Márlon Herbert Flora Barbosa Soares ${ }^{2}$
}

\begin{abstract}
Resumo: Dada a grande influência da televisão na vida dos jovens, a presente pesquisa investigou um dos gêneros televisivos que se destina ao público infanto-juvenil: os desenhos animados. Esta investigação consiste em uma análise documental com base em alguns episódios dos desenhos Jimmy Nêutron e O Laboratório de Dexter, com a intenção de detectar quais visões de ciência são veiculadas por meio destes episódios. Tal análise realiza-se sob a ótica das idéias de alguns pensadores representativos da Filosofia das Ciências, por serem estas idéias importantes para a compreensão de como se desenvolveu e tem se desenvolvido o pensamento científico em nossa sociedade. O presente artigo sugere o uso de desenhos animados como alternativa para motivar debates que privilegiem a construção do conhecimento científico com base em um universo familiar ao estudante.
\end{abstract}

Palavras-chave: Visões de ciência. Desenhos animados. Ensino de ciências.

\begin{abstract}
Because of the big influence of TV in youngsters' lives, this research seeks to investigate one kind of TV program for children and teenagers. This investigation consists of a documentary analysis of some episodes of Jimmy Neutron and The Dexter Lab cartoons with the purpose of detecting which science views are broadcast in these episodes. The analysis is made from the point of view of some representative thinkers in the philosophy of science. These ideas are important in understanding how science thinking has developed in our society. This present article shows the use of cartoons as an alternative to motivate debates which will drive the construction of scientific knowledge using an environment familiar to the student.
\end{abstract}

Keywords: Science views. Cartoons. Science teaching.

\footnotetext{
${ }^{1}$ Química. Doutoranda em Química. Docente, Unidade Universitária de Ciências Exatas e Tecnológicas, Universidade Estadual de Goiás (UEG). Goiânia, GO. <nyuara2006@yahoo.com.br>

${ }^{2}$ Químico. Doutor em Ciências (Química). Docente, Instituto de Química, Universidade Federal de Goiás (UFG). Goiânia, GO. <marlon@quimica.ufg.br>
}

\footnotetext{
${ }^{1}$ Instituto de Química, Universidade Federal de Goiás

Campus II - Caixa Postal 131 - Goiânia, GO

$74.001-970$ 


\section{Introdução}

A televisão, por ser um dos meios de comunicação mais utilizados por significativa parcela da população mundial (LOUREIRO, FONTE, 2003), é motivo de debates e discussões a respeito do seu papel e influência no contexto cultural da atualidade. Ela é vista como culpada de muitos males que afligem nossa sociedade, dentre eles podem-se citar: violência, apatia e consumismo. Já propuseram tirá-la do ar, boicotá-la ou desligá-la (CARNEIRO, 2002). Sua programação é vista, por muitos, como instrumento de alienação e transmissora da ideologia dominante. Na visão de Goergen (2001, p. 54),

A informação televisiva veio acentuar os traços do hedonismo contemporâneo dos desejos individuais da cultura do corpo, do prazer, da ilimitada promoção da subjetividade. Tudo que acontece é apresentado em forma de notícia, rápido, neutro, sem comentários com ares de amoralidade. O primado dos fatos sobre os valores caracteriza um pós-moralismo midiático, sustentado por um mito de objetividade e sensacionalismo espetacularizante que não esconde os interesses comerciais.

Esta é uma das formas de enxergar o papel da televisão no contexto atual. A questão a ser enfocada é que, mesmo levando-se em conta a função "deseducadora" atribuída a este que é o meio de comunicação mais difundido no mundo ocidental, ela é presente, constante e veio para ficar. A televisão faz parte da vida diária de milhões de pessoas nos mais diferentes locais e nas mais variadas culturas, e é mais presente na vida das crianças, atuando, muitas vezes, como "babá eletrônica". E no Brasil não é diferente. A pesquisa Kiddo's - Latin America Kids Study 2003 revela que 99\% das crianças brasileiras têm a mídia televisiva como principal veículo de entretenimento e $81 \%$ assistem à TV duas horas ou mais por dia (KIDDO'S, 2005).

Tendo em vista esta fatia do mercado, a maioria das emissoras de TV aberta destina parte de sua programação para atender ao público infanto-juvenil. Já na TV a cabo, existem canais que veiculam desenhos animados 24 horas por dia (Discovery Kids, Nickelodeon, Jetix, Disney Channel, Cartoon Network, Boomerang). A programação veiculada não prima pela qualidade, sendo criticada por pais e educadores que vêem, em alguns desenhos animados, a exacerbação do consumismo, como relata Fusari (1985, p. 146):

Enfim, esses textos audiovisuais mostraram-se atendendo mais aos interesses de lucro, caracterizando-se como mercadorias de lazer, desinformados de seu papel no campo da educação informal e de circulação informal de um sentido de existência voltado para a atuação social, entre espectadores e telespectadores adultos e crianças.

Há também a questão da violência presente nos episódios. Sobre esse aspecto, posiciona-se Merlo-Flores (1999, p. 189): 
Visões de ciência em desenhos animados: ...

A televisão, com sua carga de violência institucionalizada dá às crianças e aos jovens "permissão" para usá-la (a violência). Uma mensagem é transmitida juntamente com a forma de decodificá-la, a violência é um meio "legítimo". A agressão se tornou um novo código de comunicação, particularmente para os jovens.

Para ilustrar essa visão, podem-se citar desenhos como Dragon Ball e os Cavaleiros do Zodíaco que mostram lutas sangrentas entre os personagens principais, nas quais a violência e força física são usadas como símbolo de dominação e poder.

Dentre as emissoras da TV aberta, a TV Cultura traz uma programação de desenhos animados considerada de qualidade para a faixa etária de quatro a sete anos. Essa avaliação foi feita por intermédio do Prêmio Mídia de Qualidade 2005, promovido pela ONG Midiativa - Centro Brasileiro de Mídia para Crianças e Adolescentes. Um dos desenhos premiados foi O Pequeno Urso, que trabalha com valores relacionados à família, respeito aos animais e à natureza. Cailluo, também premiado, é um desenho animado francês em que um menino de quatro anos aprende, no dia-a-dia de sua família, as regras da boa convivência social. Nas faixas etárias de oito a 11 anos e de 12 a 17 anos, foram premiados os "melhores entre os piores": Bob Esponja e Os Simpsons, que se caracterizam por mostrar aflições comuns entre as pessoas da sociedade atual, dividida entre o ideal da solidariedade e a realidade da competição (LEAL FILHO, 2006).

Um outro ponto que deve ser ressaltado é a ausência quase que total, na TV brasileira, de produções nacionais de desenhos animados. A exceção dá-se por conta de Maurício de Souza que, desde 1976, vem produzindo filmes animados com a Turma da Mônica, direcionados para crianças até sete anos de idade (FUSARI, 1985). Nas faixas etárias de pré-adolescentes e adolescentes, a totalidade da oferta do gênero televisivo em questão é de produções estrangeiras. Dada a presença e influência dos desenhos animados na vida das crianças e adolescentes, os Parâmetros Curriculares Nacionais abordam o tema sugerindo, em seu documento de introdução, a utilização dos mesmos no processo ensino-aprendizagem:

A programação convencional de televisão, que em princípio não tem finalidade educativa, pode ser utilizada como fonte de informação para problematizar os conteúdos das áreas do currículo, por meio de situações em que o veículo pode ser um instrumento que permite observar, identificar, comparar, analisar e relacionar acontecimentos dados, cenários, modos de vida etc. Por exemplo, é possível propor estudos comparativos de personagens e ambientes de novelas, desenhos, seriados [...] Propostas desse tipo favorecem o desenvolvimento de habilidades relacionadas à linguagem oral e escrita, e de uma atitude mais crítica diante da televisão como veículo de informação e comunicação. (BRASIL, 1998a, p. 143)

Sob este enfoque, reafirma-se a importância do papel do professor. É ele que deve conduzir, com destreza e competência, o processo de aproximar a realidade da sala de aula à realidade do aluno, com o objetivo de tornar significativa a aprendizagem de conteúdos 
curriculares, pois, segundo Cortella (2004, p. 16): "Uma nova qualidade social exige uma reorientação curricular que preveja levar em conta a realidade do aluno. Levar em conta não significa aceitar essa realidade mas dela partir; partir do universo do aluno para que ele consiga compreende-lo e modificá-lo".

Os desenhos animados podem promover uma abordagem discursiva sobre estereótipos e representação do real. Rocco (1999), propõe, ao analisar a linguagem televisiva, que, "uma vez trabalhada a ludicidade que recobre o discurso desses textos, pode-se partir para o contraponto do questionamento da mensagem que é passada, iniciando um processo de crítica às figuras, aos arquétipos que nos chegam".

\section{Os desenhos animados e a ciência}

Em alguns desenhos animados, são abordados temas relacionados à ciência. Pode-se classificar estes desenhos em dois grupos: os que usam os conceitos relativos à ciência para ensinar o público telespectador (desenhos educativos), e os que não têm o compromisso com a educação, apenas usam os conceitos dentro da ludicidade da sua linguagem, dinamizando, de forma diferenciada, o texto audiovisual (desenhos criativos). Do primeiro grupo, cita-se como exemplo: Capitão Planeta (TV a cabo, canal Boomerang), Cyberchase (TV Cultura e canal Boomerang) e Ozzie e Drix (canal Cartoon Network).

Ilustra-se o segundo grupo com os desenhos O Laboratório de Dexter e Jimmy Nêutron, o menino gênio. São desenhos que trazem, como personagens principais, meninos cientistas que, muito inteligentes, usam suas invenções e criatividade para resolver situações que vão desde encrencas na escola até salvar o mundo de uma invasão alienígena. Nestes desenhos são utilizadas muitas palavras e situações relacionadas à ciência, desde laboratório, experiência, até o Princípio da Incerteza de Heisenbeg. Não são desenhos educativos, pois, na maioria das vezes, não detalham ou discutem os conceitos, mas apenas os utilizam com a intenção de divertir. Isto se observa segundo a fala do próprio criador do desenho Dexter, Tartakovsky (2005), em entrevista à Revista Época, quando perguntado se seus desenhos têm a intenção de educar ou apenas entreter:

Quando eu era criança, via muita televisão. Não acho que isso tenha me prejudicado. Ao contrário: me ajudou a aprender inglês quando cheguei de Moscou. Por isso acho que a TV pode ser educativa. Mas isso não é problema meu. Quero fazer a criança rir, e não dar lições de vida. Tenho uma filha de um ano e meio e, outro dia, ela assistiu um desenho que a deixou assustada. Fiquei chateado, não com quem fez o desenho, e sim comigo mesmo por ter deixado que ela o visse. Educar é obrigação dos pais, não da televisão.

(TARTAKOVSKY, 2005)

Verifica-se, assim, que fatos e conceitos relacionados à ciência são veiculados via televisão, e crianças e jovens acabam sendo influenciados em suas idéias a respeito do tema, como citado por Kominsky e Giordan (2002, p. 11): "acreditamos que as visões do mundo dos 
Visões de ciência em desenhos animados: ...

estudantes também devem ser influenciadas pelo pensamento científico e pelas expressões de sua cultura, cujos traços são parcialmente divulgados na mídia”. Torna-se, então, importante investigar quais visões de ciência são transmitidas pela televisão e pelos desenhos animados, e de que maneira essas visões podem interferir na concepção de mundo dos estudantes.

\section{Objetivos e métodos}

A presente investigação buscou identificar quais visões de Ciência são veiculadas por meio de desenhos animados, por se entender que a televisão tem grande alcance sobre as crianças e adolescentes, e que os desenhos animados são assistidos com freqüência pelo público infanto-juvenil. Ao trabalhar com a análise de desenhos animados, o caminho mais viável encontrado para desenvolver a pesquisa foi a análise documental, que busca identificar informações factuais nos documentos com base em questões ou hipóteses de interesse.

As hipóteses de interesse que orientaram a investigação se pautaram na busca de informações sobre a caracterização do cientista, ou seja, de que forma os desenhos animados retratam o cientista em suas ações, e como isto pode influenciar os pequenos e jovens telespectadores a respeito deste profissional atuante na pesquisa científica, contribuindo para que se perpetuem, cada vez mais, visões deformadas da atividade científica (FERNANDEZ et al., 2002). Uma outra questão investigada se refere à mitificação da ciência e da tecnologia como imprescindíveis ao processo de desenvolvimento humano, sem se abordar os danos causados por este dito indispensável progresso.

Além disso, procurou-se relacionar os desenhos com algumas visões de epistemólogos da ciência, como meio de detectar formas de como a ciência é repassada para a sociedade por meio dos desenhos animados, e de como ela é pensada pelos autores destes desenhos.

Em relação à natureza do conhecimento científico, optou-se por analisar a presença de situações, nos episódios, que sejam associadas à idéia de que a ciência começa e se desenvolve a partir de problemas e está associada à atividade experimental, sendo esta a concepção popperiana para o desenvolvimento científico. Uma outra visão de ciência analisada foi a de que só é ciência aquilo que for aceito por consenso, o que constitui uma das idéias centrais de Thomas Kuhn para o desenvolvimento científico. Há, ainda, a relação entre os programas de pesquisa de Lakatos e os episódios. $\mathrm{Na}$ idéia da ciência como programas de pesquisa, o cientista tem apego às suas teorias e não as abandona com facilidade. A última associação entre os episódios analisados e as concepções epistemológicas refere-se à visão positivista que concebe a ciência como solução para todos os problemas humanos, e valoriza a tecnologia sem se preocupar com as dificuldades geradas com base nesta valorização (MESQUITA, 2006).

Os conteúdos dos desenhos O Laboratório de Dexter e Jimmy Nêutron, o menino gênio, foram analisados, e os resultados são discutidos neste trabalho. Justifica-se esta escolha por se tratarem de desenhos que abordam temas relacionados à ciência e ao mundo científico de meninos que representam pequenos cientistas. Os episódios utilizados para esta análise foram gravados em fitas de vídeo e estão especificados na tabela I. 
Mesquita, N. A. S.; Soares, M. H. F. B.

Tabela 1. Episódios dos desenhos Jimmy Nêutron e O Laboratório de Dexter.

\begin{tabular}{cll}
\hline $\mathbf{N}^{\circ}$ do desenho & \multicolumn{1}{c}{ Título original } & \multicolumn{1}{c}{ Título em português } \\
\hline 1 & Don't be a baby & Não seja criança \\
2 & Quiet Riot & Que sono \\
3 & Dexter vs. Santa Claus & Dexter contra o Papai Noel \\
4 & Dexter Lounge & Bar do Dexter \\
5 & Gooey aliens & Gelecas alienígenas que dominam sua mente \\
6 & When pants attack & O ataque das calças \\
7 & Jimmy on ice & Jimmy no gelo \\
8 & Grumpy young man & Jovens rabugentos \\
\hline
\end{tabular}

Foram selecionados, para análise, os seguintes aspectos relacionados à ciência: caracterização do cientista (física e social); visões sobre a tecnologia e sobre a ética apresentadas nos episódios; visões de ciência dos personagens, buscando relacioná-las às visões de alguns epistemólogos da ciência.

\section{Resultados e discussão}

Ao se observarem os desenhos animados selecionados para esta análise documental, pode-se traçar o perfil do cientista representado nos episódios. Quanto à caracterização física dos personagens, Dexter usa sempre seu jaleco branco, mesmo quando vai à escola, e seus óculos enormes. Jimmy usa o jaleco branco quando precisa realizar algum experimento em seu laboratório, mas, no dia-a-dia, usa uma camiseta vermelha estampada com o símbolo do átomo de Rutherford.

Mesmo nas suas horas de folga, Dexter não deixa de lado o seu interesse pela ciência. No episódio 4, ele está cansado e necessita se distrair: "Depois de um longo dia no laboratório, um gênio também gosta de relaxar. E, ao chegar ao bar: Garçon, uma rodada de Ciência Shake para todos."

Dexter e Jimmy são garotos dedicados à ciência e que sempre trabalham sozinhos em seus experimentos, sem contar com ajuda de outros cientistas. O cientista apresenta-se, desta forma, como solitário em suas atividades. Isto configura uma visão individualista da ciência, em que os conhecimentos científicos aparecem como obras de gênios isolados (FERNANDEZ et al., 2002).

A deformação da ciência vista como individualista também foi detectada em pesquisas que analisaram histórias em quadrinhos (HQ) que veiculavam fatos relacionados ao conhecimento científico. Em cerca de 63,7\% das HQ analisadas, o trabalho científico aparece realizado por uma só pessoa (GALLEGO TORRES, 2007). É importante ressaltar que tanto os desenhos animados quanto as HQ destinam-se basicamente às atividades de distração e lazer entre crianças jovens.

Outra observação que merece destaque é a visão de que o desenvolvimento científico é papel exclusivo dos homens. Cientistas são freqüentemente representados pela figura 
Visões de ciência em desenhos animados: ...

masculina e, muitas vezes, a mulher é retratada como "do lar" - mãe do Dexter e mãe do Jimmy. A visão da atividade científica como atividade masculina é discutida por Cachapuz et al. (2005, p. 44):

Freqüentemente insiste-se, explicitamente, em que o trabalho científico é um domínio reservado a minorias especialmente dotadas, transmitindo expectativas negativas para a maioria dos alunos, e muito em particular, das alunas, com claras discriminações de natureza social e sexual: a ciência é apresentada como uma actividade eminentemente "masculina".

A idéia da ciência como eminentemente masculina é também discutida por outros autores (GALLEGO TORRES, 2007; FERNANDEZ et al., 2002), corroborando a questão, discutida neste trabalho, de que visões deformadas da ciência veiculadas nos desenhos animados tendem a influenciar os jovens telespectadores na construção de seus ideários científicos.

Os personagens Jimmy e Dexter demonstram que não se consideram iguais aos outros e, pelas suas inteligências, não merecem fazer coisas comuns, como Dexter ao ter de mexer no encanamento de sua casa para retirar uma forma de vida alienígena: "Ora, quem diria que eu, Dexter, acabaria virando um encanador". (Desenho 5)

E Jimmy, quando sua mãe manda ele arrumar o quarto e guardar suas roupas, diz ao amigo Caio: "Caio, eu sou um cientista, tenho coisa mais importante para fazer do que guardar minhas calças”. (Desenho 6)

Assim, percebe-se que os meninos cientistas representam a imagem do cientista constantemente veiculada na mídia: pessoas com inteligências acima da média, muito dedicadas às suas experiências e sem vida social ou afetiva, e que não são consideradas pessoas normais. Representação essa que é repassada para a sociedade, como se pode observar no trabalho de Kominski e Giordan (2002, p. 14), em que foi solicitado aos alunos que escrevessem sobre a forma como eles enxergavam o cientista: "em todas as representações, observa-se um cientista masculino, solitário, e interagindo somente com o seu mundo. Nas únicas cenas em que se representam outras pessoas, elas são vistas como objetos: tanto o homem como cobaia como a mulher na foto na parede".

Essa imagem estereotipada do cientista e da ciência veiculada na mídia, mais especificamente, nos desenhos animados, pode gerar um afastamento e certo preconceito, por parte dos alunos, em relação à disciplina e ao professor de ciências, o que acaba por dificultar o trabalho de construção do conhecimento científico em sala de aula. Cachapuz et al. (2005, p. 38), ao discutirem as distorções nas visões de ciência, afirmam que "visões empobrecidas criam o desinteresse, quando não a rejeição, de muitos estudantes e se convertem num obstáculo para a aprendizagem".

$\mathrm{Na}$ análise dos episódios, detectam-se algumas formas de se enfocar a ciência que se relacionam às visões de ciência que buscam explicar a forma como se construiu e se elaborou o pensamento científico ao longo dos anos. Uma das visões identificadas é a visão popperiana, segundo a qual a ciência começa com um problema (POPPER, 1982). Em todos os episódios analisados, é sempre um problema que motiva a ação científica que vai conduzir a história. No desenho 7, o calor excessivo na cidade de Retrovila leva Jimmy a usar seus 
conhecimentos científicos para desenvolver um equipamento que altera a condição climática da cidade. Já no episódio 1, Dexter precisa ficar mais velho para poder assistir um filme proibido para sua idade, e esse problema o leva ao seu laboratório para trabalhar no projeto do acelerador de idades.

Percebe-se, também, a visão falsificacionista, segundo a qual uma teoria pode ser falsificada e outra melhor vem a substituí-la gerando uma maior aproximação da verdade. E a ciência progride desta maneira, por meio de falsificações de teorias (POPPER, 1982, p. 271). Nesse sentido, os pequenos cientistas, em alguns episódios, buscam provar suas teorias e, nessa busca, surgem situações que mostram que uma teoria será aceita se outra for invalidada por intermédio de testes experimentais. No episódio 3, Dee Dee, a irmã mais velha de Dexter, acredita em Papai Noel, e ele resolve provar a ela que Papai Noel não existe. Se expressa da seguinte forma: "Eu vou mostrar a ela, antes do Natal terminar que a minha teoria é verdadeira e a dela é falsa. Papai Noel não existe". E, ao se organizar para desmascarar o bom velhinho, ele lança seu grito de guerra: "Pela ciência!"

A visão lakatosiana também está presente nos desenhos. Para Lakatos, o progresso é encaminhado por meio dos programas de pesquisa, segundo Kominski e Giordan (2002, p. 13) "quando dados experimentais discordam dos modelos propostos, o cientista não abandona imediatamente o modelo, mas, ao contrário, procura modificá-lo, mediante uma nova construção que denominou cinturão protetor".

Lakatos propõe que o cientista tem grande apelo às teorias vigentes, evitando ao máximo rejeitá-las (LAKATOS, MUSGRAVE, 1979). Nota-se esse perfil quando, mesmo que seus experimentos dêem errados, os meninos cientistas não os abandonam, procurando reestruturá-los, fazendo algumas modificações no projeto inicial para que tudo dê certo. Exemplifica-se com o episódio 8, no qual, ao testar o seu acelerador metabólico, Jimmy percebe que suas idades foram muito avançadas no tempo e, para resolver o problema, ele não abandona o plano inicial mas programa alterações: "Eu só preciso arranjar titânio suficiente para fažer um freio de tempo mais forte".

Uma outra maneira que se percebe de conceber a ciência, em alguns episódios, está associada à forma como a comunidade científica é conservadora, o que remete aos paradigmas de Kuhn, segundo os quais só são considerados ciência fatos e teorias que os cientistas aceitam por consenso (KUHN, 2001, p. 40). No episódio 2, há o seguinte diálogo entre Dexter e sua irmã Dee Dee:

"(Dexter) Eu quero dormir.

(Dee Dee) Por quê?

(Dexter) Porque enquanto você estava na sua caminha aconchegante, eu estava acordado a noite toda dando um passo à frente perante a comunidade cientifica de hoje."

A referência feita à comunidade científica subentende que, no desenho animado em questão, considera-se a existência de um corpo de cientistas que pesquisam juntos e, possivelmente, chegam a conclusões comuns, o que remete à idéia de ciência consensual citada anteriormente.

Mas a visão de ciência que se mostra mais evidente é a visão positivista, que defende a ciência e as tecnologias criadas a partir dela como solução para os problemas do homem, enfatizando o papel da experiência no desenvolvimento científico (MESQUITA, 2006; 
SCHÖN, 1998). Esta ênfase na experimentação é mostrada na importância dada ao laboratório, pois os meninos cientistas, sempre que precisam desenvolver seus experimentos, o fazem em seus laboratórios muito bem equipados; e, mesmo Jimmy Nêutron, que traja sempre uma camiseta vermelha com o desenho do átomo de Rutherford, quando vai ao laboratório, veste seu jaleco branco. Cachapuz et al. (2005), ao discutirem as visões deformadas da ciência e da tecnologia, enfocam o caráter empírico da atividade científica:

A imagem individualista e elitista do cientista traduz-se em iconografias que representam o homem da bata branca no seu inacessível laboratório, repleto de estranhos instrumentos. Desta forma constatamos uma terceira e grave deformação: a que associa o trabalho científico, quase exclusivamente, com esse trabalho no laboratório, onde o cientista experimenta e observa, procurando o feliz "descobrimento". Transmite-se assim uma visão empiro-indutivista da actividade científica. (CACHAPUZ et al., 2005, p. 45)

Nos episódios, a ciência é enaltecida e mitificada por meio de situações, ações e falas dos personagens. No desenho 1, no laboratório de Dexter, surge uma linha de montagem em que cada etapa do processo de cuidar de crianças é realizada por um equipamento diferente, enquanto os bebês vão passando numa esteira. Essa situação faz referência ao uso de tecnologias na produção industrial em larga escala.

No episódio 2, a tecnologia vem para facilitar a vida de Dexter, com controles remotos que fecham as janelas do quarto e acionam uma escada ao lado da cama alta, para que ele possa subir e se deitar. Dexter supervaloriza a ciência, como se mostra no desenho 5, em que ele conversa com uma forma alienígena e diz: "Nós temos que descobrir do que vocé é feito. Não, não diga. É para isso que servem os laboratórios".

Reconhecer as visões de ciência que permeiam o discurso implícito nos desenhos animados torna-se importante na medida em que estes discursos refletem e influenciam o pensamento das pessoas em geral; e, de forma mais evidente, influenciam as crianças e os jovens pelo fato de que estes estão formando seus conceitos e idéias sobre o mundo, e o desenho animado é um universo familiar ao jovem estudante.

Nos episódios analisados, a questão de exaltação da ciência, da tecnologia, da dependência da modernização para a resolução de problemas, tende a perpetuar a crença, que ainda existe, de que o progresso é o caminho único para o desenvolvimento humano. Mas, esta forma de pensar e de agir deve ser contestada, pois há tempos se verificou que existem os dois lados do avanço tecnológico: aquele que traz o desenvolvimento e aquele que traz a destruição. Como cita Morin (2002, p. 72):

Vimos que o desenvolvimento industrial podia causar danos à cultura e poluições mortais; vimos que a civilização do bem-estar podia gerar ao mesmo tempo mal-estar. Se a modernidade é definida como fé incondicional no progresso, na tecnologia, na ciência, no desenvolvimento econômico, então esta modernidade está morta. 
Nesse caminho, um enfoque epistemológico que contemple as origens da natureza do conhecimento científico, pode trazer esclarecimentos importantes para certos problemas que surgem no processo de aprendizagem de conceitos e teorias da ciência. Segundo Freire Jr. (2002, p. 27):

A educação em ciências enfrenta um desafio contemporâneo, ela deve contribuir para que o cidadão estabeleça uma relação crítica com a ciência e a tecnologia, relação que seja um antídoto ao ceticismo que idolatra e mitifica a ciência, como à postura irracionalista que desconhece o papel humanizador da ciência. Este desafio guarda correlação com a necessidade de que esse cidadão compreenda a ciência como parte do legado cultural. Essas são as razões maiores a recomendar o recurso às contribuições da história e da filosofia para a educação em ciências.

Ao se discutirem as implicações do avanço tecnológico no processo educacional, torna-se relevante fazer referência à questão da ética na ciência e como ela pode afetar a sociedade atual. Em alguns episódios dos desenhos animados analisados, esse tema surge com um enfoque pejorativo no qual o cientista não leva em conta as questões éticas envolvidas no procedimento por ele realizado. Tal observação pode ser exemplificada no episódio 8 , em que os meninos querem comprar um game proibido para a sua idade por ser muito violento, no qual decorre o seguinte diálogo:

"(Jimmy) Eu acho que, teoricamente, uma pessoa pode acelerar seu metabolismo para poder ter 18 anos. Mas isso não seria nada ético [...]

(Sheen) Então, o que separa a gente de ação de primeira com muitos jogadores é a diferença entre o certo e o errado?"

Os personagens optam por ignorar a questão da ética e realizam o experimento que propicia o aumento das suas idades. Levando-se em conta que a ética constitui-se em tema transversal que deve permear a educação em todos os seus níveis (BRASIL, 1998b), o exemplo acima, retirado de um desenho animado, pode ser utilizado como motivador para um debate em sala de aula sobre o que é ético e o que não é ético no mundo científico.

Salienta-se que os educadores precisam estar atentos às influências que, de modo subreptício, possam se refletir nas concepções das crianças e adolescentes em idade escolar. Mas essa deve ser também uma tarefa de todos, pois, segundo Goergen (2001, p. 82):

Enquanto a sociedade encolher os ombros e fizer ouvidos moucos com relação às barbaridades deseducativas e deformativas que, por exemplo, os meios de comunicação exercem sobre os jovens e os cidadãos de modo geral, permanecem tênues as esperanças de um futuro melhor, mais democrático, solidário, mais ético e humano, por maior que seja o empenho nesse sentido no espaço da educação formal. 
Visões de ciência em desenhos animados: ...

Mas, para conduzir uma discussão sobre este tema, com propriedade e sem correr risco de propagar idéias incorretas, ao professor de ciências não resta outra alternativa senão a de desenvolver, ao longo seu trabalho docente, o hábito do estudo, da reflexão, e o compromisso com uma educação que privilegie o ser ao invés do ter, e a compreensão ao invés da informação.

\section{Considerações finais}

De que maneira reconhecer estas visões sobre ciência que estão presentes nos desenhos animados pode contribuir para a melhoria do ensino de ciências? Argumenta-se que é imprescindível o conhecimento sobre como, e de que forma, desenvolveu-se o pensamento científico que conduziu a humanidade aos dias de hoje, pois nessa incursão ao passado, encontram-se respostas para muitas das ações do presente.

Toda reflexão sobre ensino passa pela formação do professor como sujeito atuante e necessário na construção de uma sociedade menos consumista, mais crítica, mais ética. A televisão está presente com seus programas bons e ruins. A sociedade é livre para vê-los e, muitas vezes, aqueles que os assistem não têm subsídios para assumir uma postura de questionamento frente aos seus conteúdos. É também função do professor trabalhar a multiplicidade de visões de mundo e, para isto, ele precisa ser preparado. Segundo Pretto (1996, p. 118):

Um significativo passo nessa direção é considerar, no cotidiano da sua formação, as questões da comunicação, da informação e das imagens, com o objetivo de tornar os novos profissionais preparados para vivenciar os desafios do mundo que se está construindo. Naturalmente, se estamos pensando numa escola na qual a cultura audiovisiva seja uma presença, o professor, principal personagem desse processo, precisa estar preparado para trabalhar com essa cultura. Uma cultura que está intimamente relacionada com as mídias e, por isso, exige e determina uma nova linguagem.

Questionar. Esta é a ação que se propõe com base na análise feita no desenvolvimento da presente pesquisa. Ao professor cabe a tarefa de questionar as diversas visões de ciência que são veiculadas nos meios de comunicação de forma a levar o aluno à reflexão sobre o papel da ciência em sua vida. Apresenta-se, aqui, uma alternativa para motivar essa discussão: o uso dos desenhos animados.

É uma alternativa a mais na busca de tornar o ensino de ciências um ensino significativo para a vida dos jovens. É um recurso lúdico e, como todo recurso lúdico, exige do professor também uma postura lúdica frente às situações de sala de aula. A presente proposta não pretende negligenciar outras formas de trabalho, como aulas expositivas, experimentais ou o uso de livros didáticos. Consiste em apresentar um elemento novo que venha a colaborar na construção de um conhecimento científico pertinente, para que se possa fazer da educação um caminho real para o equilíbrio do indivíduo enquanto espécie e enquanto agente social. 
Mesquita, N. A. S.; Soares, M. H. F. B.

\section{Referências}

BRASIL. Ministério da Educação e Cultura. Secretaria de Educação Fundamental.

Parâmetros curriculares nacionais: introdução. Brasília: MEC, 1998a.

Ministério da Educação e Cultura. Secretaria de Educação Fundamental.

Parâmetros curriculares nacionais: temas transversais. Brasília, 1998b.

CACHAPUZ, A. et al. A necessária renovação do ensino das ciências. São Paulo: Cortez, 2005.

CARNEIRO, V. L. Q. Televisão/vídeo na comunicação educativa: concepções e funções. In: FIORENTINI, L. M. R.; CARNEIRO, V. L. Q. TV na escola e os desafios de hoje: usos da televisão e do vídeo na escola. 2. ed. Brasília: Editora Universidade de Brasília, 2002. p. 7-45.

CORTELLA, M. S. A escola e o conhecimento: fundamentos epistemológicos e políticos. 8. ed. São Paulo: Cortez, 2004.

FERNANDEZ, I. et al. Visiones deformadas de la Ciencia transmitidas por la enseñanza. Enseñanza de las Ciencias, Barcelona, v. 20, n. 3, p. 477-88, 2002.

FREIRE, JR. O. A relevância da filosofia e da história das ciências para a formação dos professores de ciências. In: SILVA FILHO, W. J. (Org.). Epistemologia e ensino de ciências. Salvador: Arcádia, 2002. p. 13-30.

FUSARI, M. F. R. O educador e o desenho animado que a criança vê na televisão. São Paulo: Loyola, 1985.

GALLEGO TORRES, A. P. Imagen popular de la ciencia transmitida por los cómics. Revista Eureka sobre Enseñanza y Divulgación de las Ciencias, v. 4, n. 1, p. 141-51, 2007.

GOERGEN, P. Pós-modernidade, ética e educação. São Paulo: Autores Associados, 2001.

KIDDO’S. Latin AmericaKids Study. Notícia. Disponível em: < http://www.andi.org.br>. Acesso em: 16 jun. 2005.

KOMINSKI, L.; GIORDAN, M. Visões de ciências e sobre cientista entre estudantes do Ensino Médio. Química Nova na Escola, São Paulo, n. 15, p. 11-8, 2002.

KUHN, T. A estrutura das revoluções científicas. Trad. Beatriz Viana Boeira e Nelson Boeira. 6. ed. São Paulo: Perspectiva S. A., 2001.

LAKATOS, I.; MUSGRAVE, A. A crítica e o desenvolvimento do conhecimento. Trad. Octávio Mendes Cajado. São Paulo: Cultrix, 1979.

LEAL FILHO, L. L. A TV sob controle: a resposta da sociedade ao poder da televisão. São Paulo: Summus, 2006. 
Visões de ciência em desenhos animados: ...

LOUREIRO, R.; FONTE, S. S. D. Indústria cultural e educação em tempos “pósmodernos”. São Paulo: Papirus, 2003.

MERLO-FLORES, T. Por que assistimos à violência na televisão? In: CARLSSON, U. (Org.). A criança e a violência na mídia. São Paulo/Brasília: Cortez/Unesco, 1999. p. $187-215$.

MESQUITA, N. As visões de ciência nos desenhos animados Jimmy Nêutron e O Laboratório de Dexter. 2006. Dissertação (Mestrado) - Universidade Federal de Goiás, Goiás, 2006.

MORIN, E. Os sete saberes necessários à educação do futuro. 5. ed. São Paulo/ Brasília: Cortez/Unesco, 2002.

POPPER, K. Conjecturas e refutações. Trad. Sérgio Bath. 2. ed. Brasília: Editora da Universidade de Brasília, 1982.

PRETTO, N. L. Uma escola sem/com futuro. Campinas: Papirus, 1996.

ROCCO, M. T. F. Linguagem autoritária: televisão e persuasão. São Paulo: Brasiliense, 1999.

SCHÖN, D. A. El professional reflexivo: como piensan los professionales cuando actúan. Barcelona: Ediciones Paidós Ibérica, 1998.

TARTAKOVSKY, G. Entrevista. 2005. Disponível em: <www.revistaepoca.globo.com>. Acesso em: 17 jun. 2005.

Artigo recebido em novembro de 2007 e aprovado em agosto de 2008. 